\title{
MRI Brain Findings in 126 Patients with COVID-19: Initial Observations from a Descriptive Literature Review
}

\author{
(D)E. Gulko, (D) M.L. Oleksk, (D)W. Gomes, (D). Ali, (D). Mehta, (DP. Overby, (D). Al-Mufti, and (D) A. Rozenshtein
}

\begin{abstract}
BACKGROUND AND PURPOSE: Recently, numerous investigational studies, case series, and case reports have been published describing various MR imaging brain findings in patients with COVID-19. The purpose of this literature review was to compile and analyze brain MR imaging findings in patients with COVID-19-related illness.
\end{abstract}

MATERIALS AND METHODS: Literature searches of PubMed, publicly available Internet search engines, and medical journal Web sites were performed to identify articles published before May 30, 2020 that described MR imaging brain findings in patients with COVID-19.

RESULTS: Twenty-two articles were included in the analysis: 5 investigational studies, 6 case series, and 11 case reports, encompassing MR imaging of the brain in 126 patients. The articles originated from 7 different countries and were published in 14 medical journals. MR imaging brain findings included specific diagnoses (such as acute infarct, posterior reversible encephalopathy syndrome) or specific imaging features (such as cortical FLAIR signal abnormality, microhemorrhages).

CONCLUSIONS: The most frequent diagnoses made on brain MR imaging in patients with COVID-19 were acute and subacute infarcts. Other common findings included a constellation of leukoencephalopathy and microhemorrhages, leptomeningeal contrast enhancement, and cortical FLAIR signal abnormality.

ABBREVIATIONS: COVID-19 = coronavirus disease 2019; PRES = posterior reversible encephalopathy syndrome; SARS-CoV-2 = Severe Acute Respiratory Syndrome coronavirus 2

G rowing evidence suggests that coronavirus disease 2019 (COVID-19), secondary to infection with Severe Acute Respiratory Syndrome coronavirus 2 can manifest with a multitude of neurologic conditions including ataxia, seizure, acute stroke, and impaired consciousness. ${ }^{1,2}$ Since the World Health Organization declared coronavirus disease 2019 (COVID-19) a global pandemic on March 11, 2020, ${ }^{3}$ the medical literature describing COVID-19 mechanisms, manifestations, and treatments has expanded with extraordinary speed. In concordance with the World Health Organization's efforts for rapid

Received June 4, 2020; accepted after revision July 28.

From the Department of Radiology (E.G., W.G., S.A., H.M.), Division of Neuroradiology; Department of Pediatrics (P.O.); Department of Neurology (F.A.M.); and Department of Radiology (A.R.), Division of Cardiothoracic Imaging, Westchester Medical Center, Valhalla, New York; and New York Medical College (M.L.O.), Valhalla, New York.

Please address correspondence to Edwin Gulko, MD, Division of Neuroradiology, Department of Radiology, Westchester Medical Center, 100 Woods Rd, Vahalla New York, 10595; e-mail: Edwin.Gulko@wmchealth.org

- Indicates open access to non-subscribers at www.ajnr.org

Indicates article with supplemental on-line table.

http://dx.doi.org/10.3174/ajnr.A6805 distribution of data by biomedical journals during public health emergencies, ${ }^{4}$ this rapid pace has been aided by the expedited peer-review processes instituted by multiple medical journals. ${ }^{5}$ Consequently, journals representing multiple disciplines simultaneously have published numerous articles describing imaging findings in COVID-19 illness. While pulmonary disease is the best recognized morbidity associated with COVID-19, there are many reported neurologic manifestations of this infection. The purpose of this literature review was to collect, analyze, and summarize the findings on brain MR imaging reported to date in patients with COVID-19.

\section{MATERIALS AND METHODS}

Due to the rapid pace of COVID-19-related publications, many relevant articles were not yet represented on the public data bases, including PubMed, and a standard systematic review was not possible. We, therefore, adopted an ad hoc approach that included queries of PubMed, other publicly available Internet search engines (such as Google, Google Scholar, and Bing), as well as a review of journal Web sites. Our review includes only articles published before May 30, 2020. Search terms included "brain MR imaging," 
"COVID-19," "neuro," "neurology," "neurologic," and "stroke." The Web sites of major radiology journals such as Radiology, JAMA Neurology, New England Journal of Medicine, and American Journal of Neuroradiology were also reviewed to identify relevant articles. Articles were included in the review if they discussed brain MR imaging findings in patients with COVID-19. Articles were excluded if they were not yet accepted by a peerreviewed journal, pertained to pediatric patients, were not written in English, or mentioned MR imaging of the brain performed in patients with COVID-19 but did not discuss the imaging findings. All included articles were reviewed by 2 fellowship-trained neuroradiologists with Certificates of Added Qualification (E.G. and W.G.).

\section{RESULTS}

\section{Articles}

Twenty-two published articles met the inclusion criteria. There were 5 investigational studies, 6 case series, and 11 case reports (Table 1 and On-line Table). The articles originated from 7 different countries (United States, $n=6$; Turkey, $n=4$; France, $n=4$; Italy, $n=4$; United Kingdom, $n=2$; Japan, $n=1$; Canada, $n=1$ ) and were published in 14 medical journals. Some articles focused primarily on neuroimaging findings in COVID-19, while others reported neuroimaging in the context of a broader clinical report. Three of the 5 investigational studies included specifically evaluated MR neuroimaging findings in hospitalized patients with COVID$19 .^{6-8}$ The other 2 studies evaluated neurologic features in patients with Severe Acute Respiratory Syndrome coronavirus 2 (SARSCoV-2) infection ${ }^{1}$ and thrombotic complications in patients with COVID-19 with Acute Respiratory Distress Syndrome. ${ }^{9}$

Table 1: Articles describing MR imaging brain findings in patients with COVID-19

\begin{tabular}{lr}
\hline \multicolumn{2}{c}{$\begin{array}{c}\text { Manuscripts Describing MRI Brain Findings in } \\
\text { COVID-19 Patients }\end{array}$} \\
\hline Articles & 22 \\
Journals & 14 \\
Countries & 7 \\
Patients with MR imaging of the brain described & 126 \\
Investigational studies & 5 \\
Case series & 6 \\
Case report & 11 \\
\hline
\end{tabular}

Table 2: Findings on brain MR imaging in 126 patients with COVID-19

\begin{tabular}{lc}
\hline \multicolumn{1}{c}{ Imaging Finding } & No. of Cases \\
\hline Acute or subacute infarcts & 32 \\
Leukoencephalopathy & 17 \\
Cortical FLAIR signal abnormality & 15 \\
Microhemorrhages & 14 \\
Leptomeningeal enhancement & 14 \\
PRES & 4 \\
Demyelinating lesions or exacerbation of MS & 3 \\
Dural venous thrombosis & 2 \\
Signal abnormality and/or enlargement of the olfactory bulbs & 2 \\
Acute hemorrhagic necrotizing encephalopathy & 1 \\
Rhombencephalitis & 1 \\
Miller-Fisher Guillain-Barré syndrome & 1 \\
Hypoxic-ischemic encephalopathy & 1 \\
Normal findings on brain MR imaging & 19 \\
\hline
\end{tabular}

\section{Imaging Findings}

The reported brain MR imaging findings in 126 patients are summarized in Table 2. In some cases, the authors made a specific diagnosis (eg, acute infarct) without describing the specific features supporting the diagnosis. In other cases, specific imaging features were provided (such as white matter hyperintensity on FLAIR images), sometimes with a presumptive diagnosis based on these findings (eg, leukoencephalopathy). In total, there were 32 cases with acute or subacute infarcts, 4 cases of parenchymal abnormality attributed to posterior reversible encephalopathy syndrome (PRES) 2 of which were hemorrhagic, 2 cases of dural venous sinus thrombosis, 3 cases of demyelinating lesions or exacerbation of MS, 1 case of acute hemorrhagic necrotizing encephalopathy, and 1 case of hypoxic-ischemic encephalopathy. With respect to specific imaging features, there were 17 reported cases of diffuse white matter signal abnormality, broadly consistent with leukoencephalopathy, described as subcortical and deep white matter signal abnormality (3 cases), diffuse abnormality (10 cases), extensive frontal and parietal white matter signal abnormality (1 case), subcortical distribution with callosal involvement (1 case), diffuse and confluent posterior predominant white matter T2/FLAIR hyperintensities (1 case), and confluent regions of restricted diffusion with subcortical and deep hemispheric white matter (1 case). Petechial parenchymal microhemorrhages with varying distributions (cortical, juxtacortical, corpus callosum, or tracking along small cortical veins) were present in 14 cases. Leptomeningeal contrast enhancement was described in 14 cases, and cortical FLAIR signal abnormality, in 15 cases. There were 2 cases of signal abnormality and/or enlargement of the olfactory bulbs and 1 case each of T2 hyperintensitiy in the right inferior cerebellar peduncle extending into the upper spinal cord, attributed to rhombencephalitis, and cranial nerve enhancement in the setting of Miller-Fisher Guillain-Barré syndrome. There were 19 reported cases of normal brain MR imaging findings.

\section{DISCUSSION}

The most common imaging finding described across all articles was acute or subacute infarction (Figure). Acute stroke is a strong prognostic marker of poor outcome in patients hospitalized with COVID-19. ${ }^{10}$ Multiple recent reports suggest that COVID-19 is associated with acute cerebrovascular disease, including intracranial hemorrhage, large-vessel occlusion, acute ischemic stroke, and dural venous sinus thrombosis. ${ }^{11-13}$ The apparent association of COVID-19 with cerebrovascular disease may reflect an increased risk of vessel thrombosis secondary to endothelial dysfunction, inflammation, platelet activation, and stasis. ${ }^{14}$ However, the exact pathophysiology of stroke in COVID-19 remains poorly understood. For example, it is presently unknown to what extent arterial thrombosis in COVID-19 is associated with pre- 


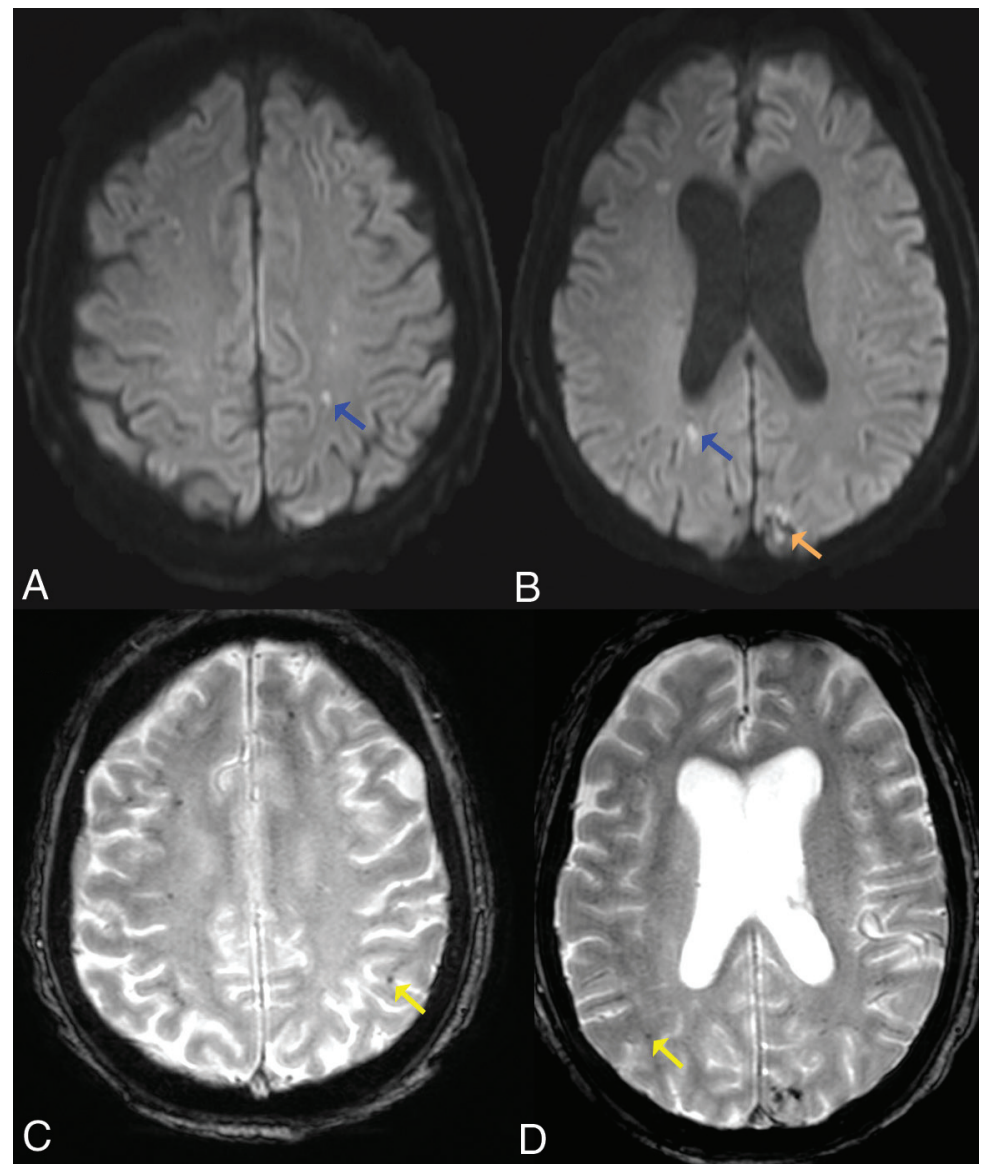

FIGURE. Acute infarcts and microhemorrhages. Axial diffusion $(A$ and $B)$ and gradient-echo $(C$ and $D)$ sequences in a 61-year-old man with COVID-19 infection. There are acute infarcts within the bilateral cerebral white matter (blue arrows) and a left occipital hemorrhagic infarct (orange arrow). There are innumerable microhemorrhages throughout the bilateral cerebral hemispheres (yellow arrows).

existing atheromatous plaque versus an entirely de novo phenomenon. It is also unclear whether thrombosis predominantly occurs in large or small arteries and, to what extent, if any, nonthrombotic vascular stenosis may contribute to the incidence of infarction.

Other commonly described findings were diffuse white matter abnormality, consistent with leukoencephalopathy, in association with parenchymal microhemorrhages. As suggested by Radmanesh et $\mathrm{al}^{7}{ }^{7}$ COVID-19 may be associated with a form of leukoencephalopathy that is particularly characterized by the presence of microhemorrhage. This could be the direct consequence of SARS-CoV-2 CNS infection or a secondary effect of a generalized COVID-19 phenomenon (such as hypercoagulability). In addition, as postulated by Radmanesh et al, it may be a late complication of critically ill patients with COVID-19 secondary to hypoxia and possibly a manifestation of delayed posthypoxic leukoencephalopathy. Of note, all patients described by Radmanesh et al and most studied by Kandemirli et $\mathrm{al}^{6}$ were intubated. Furthermore, the cohort studied by Radmanesh et al was mechanically ventilated for a mean duration of 27 days. In their study, Radmanesh et al observed mild restricted diffusion within white matter regions of $\mathrm{T} 2$ hyperintensities, the same imaging characteristics seen with delayed posthypoxic leukoencephalopathy. ${ }^{15}$
Nicholson et $\mathrm{al}^{16}$ observed multifocal, predominantly petechial hemorrhages in patients with COVID-19 and speculated that they may have resulted from diffuse thrombotic microangiopathy, which has previously been reported to cause similar abnormalities ${ }^{17}$ and can lead to PRES. ${ }^{18}$ Several studies have recently described cytokine storms in COVID-19 infection, ${ }^{19,20}$ with resultant vascular endothelial damage, ${ }^{21}$ which can result in thrombotic microangiopathy. Nicholson et $\mathrm{al}^{16}$ further suggested that extracorporeal membrane oxygenation therapy may contribute to parenchymal brain abnormalities in COVID-19 due to obligatory anticoagulation with resultant hemorrhage. However, Radmanesh et $\mathrm{al}^{7}$ described extensive microhemorrhage in a cohort that did not receive extracorporeal membrane oxygenation.

Other brain MR imaging findings in patients with COVID-19 were leptomeningeal contrast enhancement and cortical FLAIR signal abnormality, either separately or in combination. Leptomeningeal contrast enhancement is a known manifestation of leptomeningitits and has been seen in other viral illnesses such as H1N1-associated encephalitis. ${ }^{22}$ Cortical FLAIR signal abnormality has a broad differential diagnosis and can include encephalitis, postictal state, PRES, as well as acute ischemia.

Despite the global reach of the pandemic and the vast number of critically ill patients, the small number of reported cases with brain MR imaging abnormalities is likely due to stringent policies on the use of MR imaging in patients with COVID-19. The American College of Radiology recently issued recommendations for practitioners to minimize the use of MR imaging in patients infected or suspected of having COVID-19 infection unless absolutely necessary. ${ }^{23}$ Similar policies are likely to be in effect worldwide, limiting MR imaging use to patients with COVID-19 with the highest clinical urgency. This policy may, at least in part, explain most of the patients in the published reports being severely ill, many of them mechanically ventilated. It would be necessary to perform brain MR imaging examinations in symptomatic patients with COVID-19 with mild and moderate illness to determine the full spectrum of central nervous system involvement in this disease.

In addition to the small number of reported cases, our study is necessarily limited by data accessibility. Our searches of the main on-line data bases missed a substantial portion of existing COVID-19-related reports. Therefore, we added manual 
searches of multiple journal Web sites. As a result, our search results are likely not reproducible. Articles were often identified ahead of publication and before assignment of a PubMed number. Consequently, some relevant articles may have been missed.

\section{CONCLUSIONS}

In this descriptive literature review, the most frequent diagnoses made at brain MR imaging in patients with COVID-19 were acute and subacute infarcts. Other common findings included a constellation of leukoencephalopathy and microhemorrhages, leptomeningeal contrast enhancement, and cortical FLAIR signal abnormality. Because these results are preliminary, a formalized systematic review following the Preferred Reporting Items for Systematic Reviews and Meta-Analyses guidelines will be needed as more articles are published.

\section{REFERENCES}

1. Helms J, Kremer S, Merdji H, et al. Neurologic features in severe SARS-CoV-2 infection. N Engl J Med 2020;382:2268-70 CrossRef Medline

2. Mao L, Jin H, Wang M, et al. Neurologic manifestations of hospitalized patients with coronavirus disease 2019 in Wuhan, China. JAMA Neurol 2020 April 10. [Epub ahead of print] CrossRef Medline

3. Cucinotta D, Vanelli M. WHO declares COVID-19 a pandemic. Acta Biomed 2020;91:157-60 CrossRef Medline

4. Modjarrad K, Moorthy VS, Millett P, et al. Developing global norms for sharing data and results during public health emergencies. PLoS Med 2016;13:e1001935 CrossRef Medline

5. Li X, Qian Y, Liu B, et al. Helping the radiologist: the role of scientific journals to help prevent the spread of COVID-19. Radiology 2020;295:E4 CrossRef Medline

6. Kandemirli SG, Dogan L, Sarikaya ZT, et al. Brain MRI findings in patients in the intensive care unit with COVID-19 infection. Radiology 2020 May 8. [Epub ahead of print] CrossRef Medline

7. Radmanesh A, Derman A, Lui YW, et al. COVID-19-associated diffuse leukoencephalopathy and microhemorrhages. Radiology 2020 May 21. [Epub ahead of print] CrossRef Medline

8. Mahammedi A, Saba L, Vagal A, et al. Imaging in neurological disease of hospitalized patients with COVID-19: an Italian multicenter retrospective observational study. Radiology 2020 May 21. [Epub ahead of print] CrossRef Medline

9. Helms J, Tacquard C, Severac F, et al; CRICS TRIGGERSEP Group (Clinical Research in Intensive Care and Sepsis Trial Group for Global Evaluation and Research in Sepsis). High risk of thrombosis in patients with severe SARS-CoV-2 infection: a multicenter prospective cohort study. Intensive Care Med 2020;46:1089-98 CrossRef

10. Jain R, Young M, Dogra S, et al. COVID-19 related neuroimaging findings: a signal of thromboembolic complications and a strong prognostic marker of poor patient outcome. J Neurol Sci 2020;414:116923 CrossRef Medline

11. Radmanesh A, Raz E, Zan E, et al. Brain imaging use and findings in COVID-19: a single academic center experience in the epicenter of disease in the United States. AJNR Am J Neuroradiol 2020;41:1179-83 CrossRef Medline

12. Oxley TJ, Mocco J, Majidi S, et al. Large-vessel stroke as a presenting feature of COVID-19 in the young. $N$ Engl J Med 2020;382:e60 CrossRef Medline

13. Hughes C, Nichols T, Pike M, et al. Cerebral venous sinus thrombosis as a presentation of COVID-19. Eur J Case Rep Intern Med 2020;7:001691 CrossRef Medline
14. Bikdeli B, Madhavan MV, Jimenez D, et al; Global COVID-19 Thrombosis Collaborative Group, Endorsed by the ISTH, NATF, ESVM, and the IUA, Supported by the ESC Working Group on Pulmonary Circulation and Right Ventricular Function. COVID-19 and thrombotic or thromboembolic disease: implications for prevention, antithrombotic therapy, and follow-up: JACC state-of-theart review. J Am Coll Cardiol 2020;75:2950-73 CrossRef Medline

15. Zamora CA, Nauen D, Hynecek R, et al. Delayed posthypoxic leukoencephalopathy: a case series and review of the literature. Brain Behav 2015;5:e00364 CrossRef Medline

16. Nicholson P, Alshafai L, Krings T. Neuroimaging findings in patients with COVID-19. AJNR Am J Neuroradiol 2020 June 11. [Epub ahead of print] CrossRef Medline

17. Ellchuk TN, Shah LM, Hewlett RH, et al. Suspicious neuroimaging pattern of thrombotic microangiopathy. AJNR Am J Neuroradiol 2011;32:734-38 CrossRef Medline

18. Hawley JS, Ney JP, Swanberg MM. Thrombotic thrombocytopenic purpura-induced posterior leukoencephalopathy in a patient without significant renal or hypertensive complications. J Postgrad Med 2004;50:197-99

19. Ye Q, Wang B, Mao J. The pathogenesis and treatment of the "cytokine storm" in COVID-19. J Infect 2020;80:607-13 CrossRef Medline

20. Mehta P, McAuley DF, Brown M, et al. HLH Across Speciality Collaboration, UK. COVID-19: consider cytokine storm syndromes and immunosuppression. Lancet 2020;395:1033-34 CrossRef Medline

21. Teijaro JR, Walsh KB, Cahalan S, et al. Endothelial cells are central orchestrators of cytokine amplification during influenza virus infection. Cell 2011;146:980-91 CrossRef Medline

22. Haktanir A. MR imaging in novel influenza $A(H 1 N 1)$-associated meningoencephalitis. AJNR Am J Neuroradiol 2010;31:394-95 CrossRef Medline

23. ACR Guidance on COVID-19 and MR Use. https://www.acr.org/ Clinical-Resources/Radiology-Safety/MR-Safety/COVID-19-and-MRUse. Accessed May 31, 2020

24. Dogan L, Kaya D, Sarikaya T, et al. Plasmapheresis treatment in COVID-19-related autoimmune meningoencephalitis: case series. Brain Behav Immun 2020;87:155-58 CrossRef Medline

25. Tunç A, Ûnlübaş Y, Alemdar M, et al. Coexistence of COVID-19 and acute ischemic stroke report of four cases. J Clin Neurosci 2020;77:227-29 CrossRef Medline

26. Beyrouti R, Adams ME, Benjamin L, et al. Characteristics of ischaemic stroke associated with COVID-19. J Neurol Neurosurg Psychiatry 2020;91:889-91 CrossRef Medline

27. Franceschi AM, Ahmed O, Giliberto L, et al. Hemorrhagic posterior reversible encephalopathy syndrome as a manifestation of COVID19 infection. AJNR Am J Neuroradiol 2020;41:1173-76 CrossRef Medline

28. Cavalcanti DD, Raz E, Shapiro M, et al. Cerebral venous thrombosis associated with COVID-19. AJNR Am J Neuroradiol 2020 June 18. [Epub ahead of print] CrossRef Medline

29. Moriguchi T, Harii N, Goto J, et al. A first case of meningitis/encephalitis associated with SARS-coronavirus-2. Int J Infect Dis 2020;94:55-58 CrossRef Medline

30. Sachs JR, Gibbs KW, Swor DE, et al. COVID-19-associated leukoencephalopathy. Radiology 2020 May14. [Epub ahead of print] CrossRef Medline

31. Pilotto A, Odolini S, Masciocchi S, et al. Steroid-responsive encephalitis in coronavirus disease 2019. Ann Neurol 2020 May17. [Epub ahead of print] CrossRef Medline

32. Poyiadji N, Shahin G, Noujaim D, et al. COVID-19-associated acute hemorrhagic necrotizing encephalopathy: CT and MRI features. Radiology 2020;296:E119-20 CrossRef Medline

33. Wong PF, Craik S, Newman P, et al. Lessons of the month 1: a case of rhombencephalitis as a rare complication of acute COVID19 infection. Clin Med 2020;20:293-94 CrossRef Medline 
34. Zanin L, Saraceno G, Panciani PP, et al. SARS-CoV-2 can induce brain and spine demyelinating lesions. Acta Neurochir (Wien) 2020;162:1491-94 CrossRef Medline

35. Kaya Y, Kara S, Akinci C, et al. Transient cortical blindness in COVID-19 pneumonia; a PRES-like syndrome: case report. J Neurol Sci 2020;413:116858 CrossRef Medline

36. Laurendon T, Radulesco T, Mugnier J, et al. Bilateral transient olfactory bulbs edema during COVID-19-related anosmia. Neurology 2020;95:224-25 CrossRef Medline
37. Chougar L, Mathon B, Weiss N, et al. Atypical deep cerebral vein thrombosis with hemorrhagic venous infarction in a patient positive for COVID-19. AJNR Am J Neuroradiol 2020 June18. [Epub ahead of print] CrossRef Medline

38. Avula A, Nalleballe K, Narula N, et al. COVID-19 presenting as stroke. Brain Behav Immun 2020;87:115-19 CrossRef Medline

39. Politi LS, Salsano E, Grimaldi M. Magnetic resonance imaging alteration of the brain in a patient with coronavirus disease 2019 (COVID-19) and anosmia. JAMA Neurol 2020 May 29. [Epub ahead of print] CrossRef Medline 